\title{
DESIGN AND OPERATIONS CHALLENGES OF A SINGLE TOGGLE JAW CRUSHER: A REVIEW
}

\author{
C. Okechukwu'1, ${ }^{*}$, O. A. Dahunsi' ${ }^{2}$, P. K. Oke ${ }^{3}$, I. O. Oladele ${ }^{4}$, M. Dauda ${ }^{5}$ and B. M. Olaleye ${ }^{6}$ \\ 1,5 Advanced Manufacturing Technology Programme, Jalingo, Taraba State, NigERia. \\ 2, 3 Department of Mechanical EngineERIng, Federal University of TeChnology, AKURe, Ondo State, NiGERIA. \\ ${ }^{4}$ Dept. of Metallurgical and Materials Engr., Fed. University of TeChNology, AKure, ONDo State, NiGERIA.

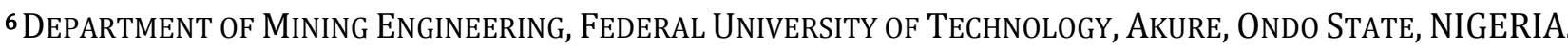 \\ E-mail addresses:1 okerex2002@yahoo.com,2oadahunsi@futa.edu.ng,3okekayode2002@gmail.com, \\ ${ }_{4}^{4}$ wolesuccess2000@yahoo.com, ${ }^{5}$ mdsmatt@gmail.com, 6 olaleyebolu@gmail.com
}

\begin{abstract}
$A$ review on the design and operations challenges of a single toggle jaw crusher is presented. Strength and fracture toughness of the material to be crushed are intrinsic properties that determine the time and energy required to crush the material. Economy of the crushing process is partly dependent on the angle of nip. Productivity of the crusher can be improved upon by increasing the eccentricity of the eccentric shaft, use of reversible jaws, bush bearing and easily adjustable toggle plate. Vibrations and fatigue cracks in the crusher frame will be nipped in the bud through structural analysis at design stage. Determination of the optimal angle of inclination of the toggle plate, development of jaws with varying wear rate along the crushing chamber, and development of comminution energy models that take into cognizance relevant crushing parameters for simulation and optimization of the crushing process are some areas that require close attention.
\end{abstract}

Keywords: Design; Operations; Jaw crusher; Challenges; Crushing parameters

\section{INTRODUCTION}

Crushing is the first mechanical comminution process after blasting of rocks and breaking of oversize rocks or boulders into crushable lumps. It involves reducing the lumps of rocks or ores into definite smaller sizes [1]. Production of economically desirable sizes is the main objective in the aggregate industry, while liberation of the valuable minerals from the gangue is the ultimate aim in mineral processing. According to Choudaha et al. [2]; Shrivastava and Sharma [3], crushers used in mining operations are commonly classified by the degree to which they fragment the feed material with primary and secondary crushers handling coarse materials and tertiary and quaternary crushers reducing ore particles to finer gradations.

The type of crusher to be used for a given job is dependent on the nature of material to be crushed, area of application of the material, maintenance and operational costs, power consumption, vibration, noise and environmental issues [4]. More so, crushers can be classified on the basis of the breaking forces as: (a) impact crushers e.g. hammers and rotor impactors [4, 5]; (b) compressive crushers e.g. jaw, gyratory, cone and roll crushers $[6,7]$.

Jaw crushers are commonly used as both primary and secondary crushers [8]. Donovan [9] noted that there are three types of jaw crushers, namely: Blake, Dodge and Universal jaw crushers; these are classified according to the location of the pivot point of the movable or swing jaw. Zeng and Forssberg [10] summarized the crusher types with the following diagrams: Figures $1 \mathrm{a}, 1 \mathrm{~b}$ and $1 \mathrm{c}$. While the Dodge crusher is restricted to laboratory use where close sizing is required and as it chokes very easily; the universal crusher has variable feed and discharge area with its pivot at the intermediate; and the Blake crusher is of two types, viz: single toggle and double toggle jaw crushers. The single toggle swing jaw is suspended on the eccentric shaft, which allows a lighter, more compact design than with the double toggle crusher [10]. Moreover, the single toggle crusher is taking over most new applications due to lower cost and higher capacity; hence the need to carry out a wholistic review of the critical aspects of the machine that requires close attention during its design and operations stages; 
this is being done with a view to revealing ways to improve its performance.

\subsection{Overview of Crushing Process in A Single Toggle Jaw Crusher}

The feed supplied to a single toggle jaw crusher through its gape, is crushed by the compression of the feed by the movable jaw against the fixed or stationary jaw. Movement of the movable jaw is controlled at the top by an eccentric shaft, which is driven by a pulley whose weight is counter-balanced by a flywheel at the opposite end of the eccentric shaft. The flywheel stores energy on the idling half of the stroke and delivers it on the crushing half [10]. Through alternate nipping and releasing of the feed, the jaws reduce the material in stages in the crushing chamber to sizes smaller than the discharge aperture or set, and the crushed product exits by gravity and with the aid of the movement of lower end of the movable jaw, which is controlled by toggle plate and drawback rod. Figure 2 shows the components of a single toggle jaw crusher.

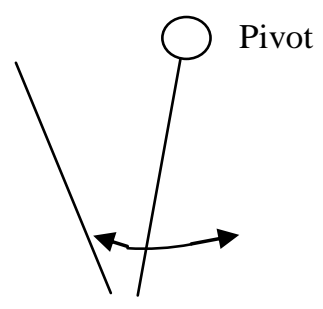

Figure 1a: Blake Crusher

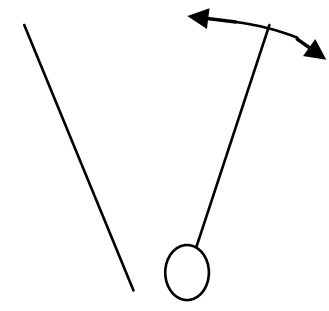

Figure 1b: Dodge Crusher

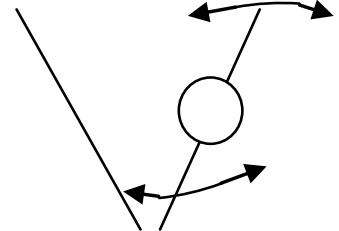

Figure 1c: Universal Jaw Crusher

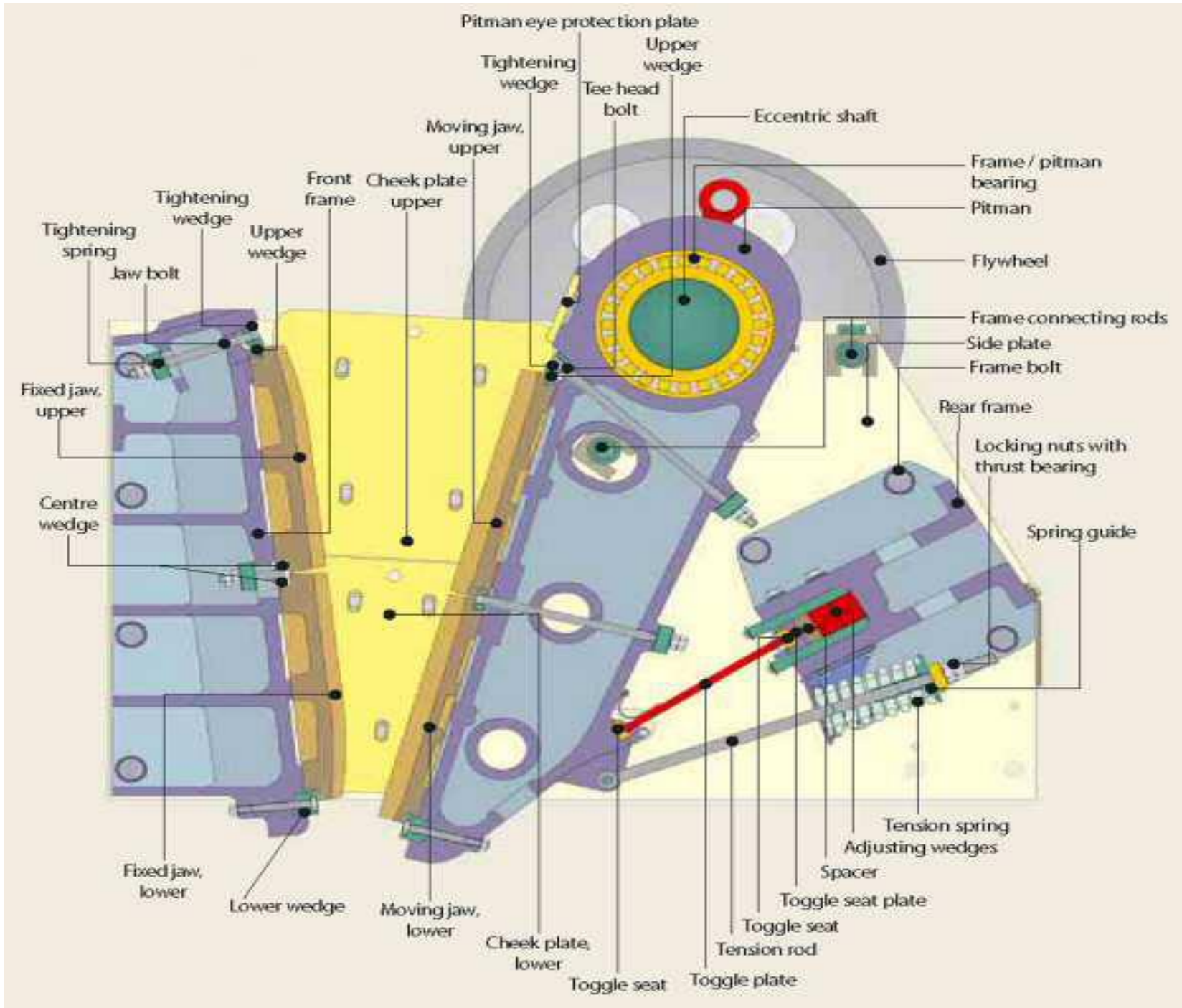

Figure 2: Cross-section of Nordberg single series jaw crusher [11] 


\section{IMPORTANT DESIGN AND OPERATION FACTORS}

There are some design and operation factors that must be given attention in jaw crushers at the design and operation stages, without which, the machine will not function economically. Such factors and critical components include: the nature of feed material, angle of nip, jaws, pitman, eccentric shaft, toggle plate, drawback rod, cheek plates, bearing, crusher frame, pulley and flywheel.

\subsection{Nature of Feed Material}

Crushers which comminute by compression are strongly recommended for hard, brittle and abrasive rocks, i.e., rocks with Mohs hardness value ranging from 6 to 7 and above [6]. Donovan [9] posited that the crushing force must exceed the fracture strength of a particle for it to fracture; however, rocks broken in jaw crushers fail at stress levels well below the compressive strength due to induced tensile stresses and the presence of cracks. It is the tensile strength of rock material that must be exceeded in order for it to fracture. Decrease in strength of rocks is due to pre-existing flaws and cracks within the rocks which act as stress concentrators as well as moisture effect on the mineral grains [12]. Refahi et al. [13] showed that the difference between Wall and Bond energies for hard rocks are more than those of lower strength rocks; this arose due to more sensitivity of the hard rock to stress concentration and strain rate.

According to Elisante [14], physical properties of materials such as: moisture content, structure, friability, density, hardness and crushing strength are important design criteria, as these affect both the life of the liners and power requirement. Olaleye [15] revealed that the higher the strength of a rock, the higher the crushing time under the influence of a crusher; this implies more wear to the crusher jaws. Donovan [9], noted that rocks are brittle materials and the theoretical strength $\sigma_{t}$ of an ideal brittle material should be approximately,

$$
\sigma_{\mathrm{t}}=\frac{\mathrm{E}}{10}
$$

where, E is Young's modulus.

However, the actual tensile strength of the rock is well below the estimate by equation (1), by at least 100 times lower.

\subsection{Angle of Nip}

The jaws are set at an acute angle to each other. This angle commonly known as the "angle of nip" is usually less than $26^{\circ}$. This is due to slipping effect when the angle is larger which reduces capacity [10]. Niemela and Kieranen [4], stated that a desirable nip angle controls the ability to crush a given type of material at a commercial rate and it preferably falls between $17^{\circ}$ and
27․ Exceeding the maximum angle causes regurgitation or slipping from the machine, while operating below the desired range leads to the production of undesirable dust and fines; hence, the machine tends to serve more like a pulverizer. Figure 3 illustrates the angle of nip in a jaw crusher.

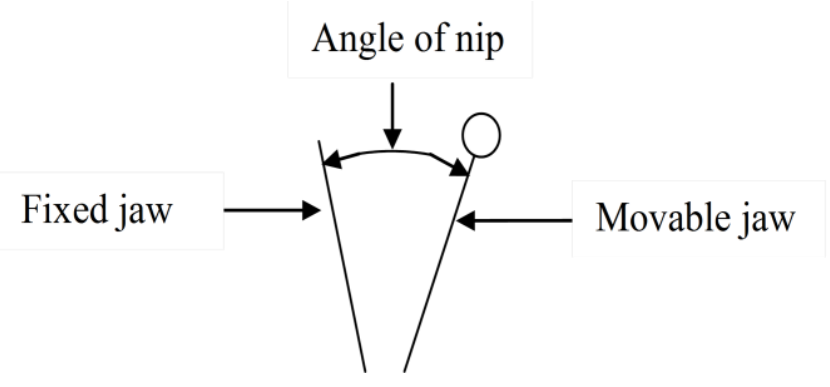

Figure 3: Angle of nip in a jaw crusher

\subsection{Crusher Jaw Plates}

Compression of materials undergoing crushing in a jaw crusher is achieved when the movable jaw presses the feed against a stationary jaw. These jaws can be flat surfaced or corrugated. Crusher jaws were formerly made of white cast iron and later with high manganese austenitic steel also known as Hadfield steel, which is the dominant wear material for the jaws. Wear on these components increases as the feed lump is being reduced and moved towards the discharge.

According to Kinkel [16], the greatest amount of crushing is done at the lower edges of the jaws; consequently, these lower edges are subjected to much greater wear than any other part of the jaw, because, the greatest movement of the movable jaw is at the lower edge. These plates are made reversible, so that the worn end can be inverted to become the upper end of the plate, thereby, reducing the cost of replacing these worn jaws. The variation in the amount of wear on the fixed jaw calls for a variation in the surface hardness of the jaw. This will be difficult to achieve by casting, but can definitely be achieved by hardfacing techniques.

Additionally, virtual modeling results have shown that the strength to weight ratio of the movable jaw can be increased by increasing the number of stiffeners attached to its back [17]; this is depicted in Figure 4. The fixed jaw is bolted to a support plate, while the movable jaw is bolted to the pitman for easy dismantling when they are worn out, to be replaced or partly worn, to be inverted.

\subsection{Pitman}

The pitman is journalled at the upper end to accept the eccentric shaft [18]. This structure houses the eccentric lobe and supports the movable jaw. The lower end of the pitman is guided by the toggle plate and drawback rod 
attached to it. It has been demonstrated by Sutti and Jonkka [19] that a pitman with a cross-sectional support in the form of a honeycomb structure reduces or removes bending of the pitman and wear compared with a pitman without such support. The cross-sectional supports eliminate bending and distortion horizontally, with additional advantages including crushing material with smaller stroke count and smaller stroke length, reduction in the amount of energy required from the flywheel, lesser material requirement for producing the pitman, reduced mass of the pitman and avoidance of holes arising from casting, when open structured pitman is used.

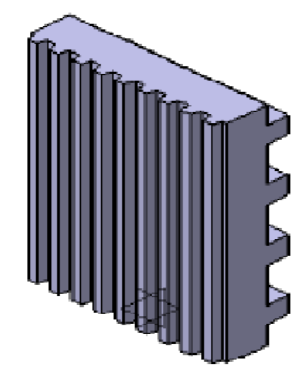

Figure 4: Movable jaw plate with stiffeners

\subsection{Eccentric Shaft}

Rotation of the eccentric shaft during operation by the pulley causes the movable jaw to make an elliptical movement. Karra et al. [18] revealed that increased eccentricity of the shaft leads to increase in throw; hence, increase in throughput capacity can be achieved without increasing the physical size of the jaw crusher by increasing the stroke of the eccentric shaft, decreasing the speed without increasing the crushing force through increased jaw width. Also, increased throw gives the advantages of retaining the structural design of the crusher and decreasing the machine loads. The crusher stroke is the displacement of jaw between the widest and narrowest points on an eccentrically gyrating cycle. Alternatively, Donovan [9] defined the throw as the stroke of the swing jaw or the difference between the open side set and the closed side set. The open side set is the maximum discharge aperture, while the closed side set is the minimum discharge aperture.

\subsection{Cheek Plates}

The side or cheek plates are positioned on the left and right ends of the crushing chamber to prevent the material being crushed from reaching the frame of the crusher, which will lead to the wear of the frame. Cheek plates are also made of manganese steel; materials such as white cast iron and hardfaced steel can be used since the impact on the side plates is minimal compared to the stationary jaw. Worn cheek plates together with worn jaws should be replaced on time as worn chamber will affect the capacity of the crusher, size and shape of the produced particles [20].

\subsection{Toggle plate}

The toggle plate is used to hold the lower part of the jaw in position; this depends on the desired product size. Toggles are designed to be adjustable for easy removal of uncrushable object such as tramp iron and to achieve proper discharge setting. Mechanisms for toggle adjustment include: spring relief mechanism for relieving strain on the jaws when tramp iron lodges between the jaws [21], shims and hydraulic cylinders, which allow easy adjustment of discharge setting by moving the toggle block to the desired setting [22], remote controlled electromechanical actuation mechanism is possible. A trial mechanism design with different acute angles of inclination showed that the throw is not only related to the eccentric shaft, but also the toggle inclination. Considering the role of the toggle plate, there is need to determine the optimal angle of inclination for efficient performance.

\subsection{Drawback or Tension Rod-Spring Mechanism}

The drawback rod is attached to the lower end of the movable jaw or the pitman carrying the movable jaw, and carries a spring at the opposite end. The rod-spring subassembly retrieves the movable jaw from the furthest end of travel. Here, the spring deflection and the rigidity of the rod are pertinent. This spring-biased rod facilitates the cyclical return of the lower end of the jaw to the base position [18].

\subsection{Pulley and Flywheel}

The weights of these two machine elements need be balanced as any deviation may lead to undesired twisting of the eccentric shaft and increased vibration. They are firmly keyed to the opposite ends of the eccentric shaft. Usually, they are made of gray cast iron because of its good vibration damping, machinability and resistance to sliding wear [23]. The pulley has two or more grooves and is driven by belts attached to the prime mover which may be a combustion engine or an electric motor. The flywheel supplies the moment of inertia of a system [24], as it serves as a reservoir, which stores energy during the period when the supply is more than the requirement and releases it when the energy requirement is more than the supply [25]. Hence, the inertia required to crush a material in a jaw crusher is provided by the flywheel [2].

\subsection{Bearing}

Bearings hold the eccentric shaft in position and enable its free rotation. Lubrication of these elements with grease and sealing of their ends should be ensured to 
prevent entry of dust. Dynamic loads from the pitman, movable jaw, flywheel, pulley, drawback rod, toggle plate and eccentric shaft lead to severe wear in the bearings. Choudaha et al. [2] demonstrated that replacing a roller bearing with bush/babbited bearing in two halves, increased the availability of a jaw crusher by $17 \%$, reduced breakdown and mean time to repair by $89 \%$, while the maintenance was reduced by $86 \%$. Also, this increased customer satisfaction and enhanced productivity as removal of the pulley and flywheel before changing the bearing was avoided. The bush bearing is as shown in Figure 5.

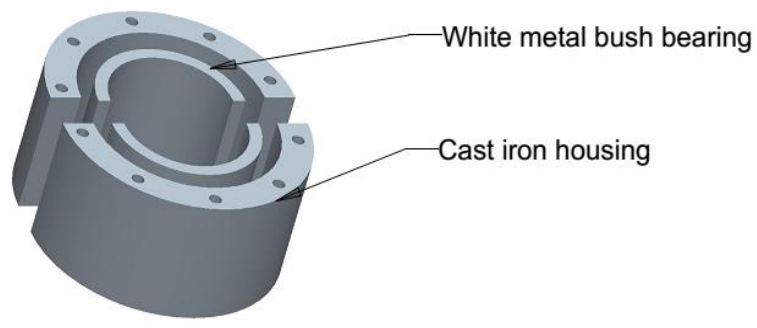

Figure 5: Bush bearing [2]

According to Didyk and Aratskiy [26], the use of natural minerals such serpentine powder as friction geomodifiers in depreciated tribological units recovery, without a shutdown of operating equipment, reduces significant maintenance costs related to equipment repair and increases the service life of machineries and mechanisms.

\subsection{Crusher Frame}

Strong foundation to accommodate vibrations arising from the alternate loading and release of stresses in the jaw crusher has been advocated by Zeng and Forssberg [10]. Rusiński et al. [27] posited that high dynamic forces are present during operation of crushers. The entire load is transferred to the supporting structures and foundations during operation. Loads on the crusher frame must be taken into consideration at the design stage and attention should be given to modal parameters of the structure to prevent possible resonance problems. Finite element method has been used to identify the cause of resonance and fatigue cracks in a jaw crusher structure. Additional side bracings and replacement of existing longitudinal bracings resolved these problems. The key to this solution method is that incorporating diagonal bracing inside the frame increases the stiffness, which results in the increase in natural frequency, $\mathrm{w}_{\mathrm{o}}$ in agreement with equation (2).

$$
\mathrm{w}_{\mathrm{o}}=\sqrt{\frac{\mathrm{k}}{\mathrm{m}}}
$$

where, $\mathrm{k}$ is the stiffness $(\mathrm{N} / \mathrm{m})$, and $\mathrm{m}$ is mass $(\mathrm{kg})$.
Taking into account equation (2), either the crusher support can be stiffened to increase the natural frequencies or additional mass can be placed on the frame to increase vibration frequency [27]. The problems of vibrations and fatigue cracks underscore the relevance of proper structural analysis at the design stage, prior to construction and operation.

\section{REVIEW OF JAW CRUSHERS' DESIGN MODELS}

The major problem in the design of comminution equipment is that most of the energy input to a crushing or grinding machine is absorbed by the machine itself and only a small fraction of the total energy is available for breaking the material. All the theories of comminution assume that the material is brittle [28]. The cost of power is a major expense in crushing, so the factors that control cost are to be given important considerations. An ideal crusher would have a large capacity; require a small power input per unit of product and yield a product of the single size distribution desired [29].

In virtually all size reduction machines, the breakage forces are either by compression or impact. The jaw crushers cause fracture by compression, since this is the most practical method of applying a fracture force to large particles. The reduction ratio is a measure of the extent of size reduction, and is defined as the ratio of the feed size to the product size. Single toggle jaw crushers have sizes ranging from $125 \times 150 \mathrm{~mm}$ to $1600 \times 2100$ $\mathrm{mm}$; power requirements from 2.25 to $400 \mathrm{~kW}$; speed from 120 to $300 \mathrm{rpm}$; and reduction ratio from 4:1 to 9:1[30].

Given that, the power required to crush a given feed size of ore or stone to product is $\mathrm{P}(\mathrm{kW})$, (tonnes/hr) is the feed rate to crusher $\dot{\mathrm{m}}$ (tonnes/hr), the $80 \%$ passing size of the feed (i.e. before breakage) is $\mathrm{D}_{\mathrm{f}}(\mathrm{mm})$, the $80 \%$ passing size of the product (i.e. after breakage) is $\mathrm{D}_{\mathrm{p}}$ $(\mathrm{mm})$, the power required to crush a tonne/hr of the material if $80 \%$ of the feed pass a $D_{f}-$ inch screen and $80 \%$ of the product pass a $D_{p}$ - inch screen, can be determined from the modified Bond equation:

$$
\mathrm{N}_{\mathrm{c}}=47\left(\frac{\mathrm{R}-1}{\mathrm{R} \cdot \mathrm{x}}\right)^{1 / 2}
$$

where, $\mathrm{W}_{\mathrm{i}}$ is the work index and is defined as the gross energy required in $\mathrm{kWhr} / \mathrm{ton}$ of feed to reduce a very large feed (infinite size) to such a size that $80 \%$ of the product passes a $100 \mu \mathrm{m}$ screen [29].

Equation (3) is used to calculate the motor size necessary to carry out the operation (a larger motor being required for a harder ore, and a smaller motor for a soft ore): that is, compression crushers match power with ore hardness, $\mathrm{W}_{\mathrm{i}}$. The work index is a measure of the ore hardness and the mechanical efficiency. Since granite will be used at the validation stage of this project; 
it is pertinent to note that the Bond work index for granite is $15.83 \mathrm{kWhr} /$ ton [30].

According to Kelly and Spottiswood [30], Rose and English observed that the critical speed $\mathrm{N}_{\mathrm{c}}$ (rpm) that produces the maximum throughput in a jaw crusher is given by:

$$
\mathrm{N}_{\mathrm{c}}=47\left(\frac{\mathrm{R}-1}{\mathrm{R} \cdot \mathrm{x}}\right)^{1 / 2}
$$

where, $\mathrm{R}$ is the reduction ratio or the ratio of the gape to the set and $\mathrm{x}$ is the throw of crusher, $\mathrm{m}$.

Comparison of this theory with manufacturer's data suggests that recommended speeds are lower than $\mathrm{N}_{\mathrm{c}}$ for the smallest and largest gapes, where the manufacturer's data was estimated from the empirical relation:

$$
\mathrm{N}_{\text {op }}=280 \exp \left(-0.212 \mathrm{G}^{3}\right)
$$

where, $\mathrm{N}_{\text {op }}$ is the operating speed (rpm) and $\mathrm{G}$ is the gape setting, $\mathrm{m}$.

This study concluded that jaw crushers were not designed with adequate mechanical power, thereby limiting the maximum throughput achievable at respective operating speeds.

Karra et al. [18] revealed that it is preferable to increase the throw to a greater degree than any reduction in speed in order to increase capacity while decreasing the machine load. Also, the horsepower being the amount of power consumed is a function of stroke, crushing force and eccentric speed; hence, conventional crusher design theory dictates that:

Horsepower $=$ crushing force $\mathrm{x}$ stroke $\mathrm{x}$ RPM

According to More and Rajpal [31], Ashok and Yan gave the following models for the design of crusher jaws: Width $(\mathrm{W})$ of jaw plate lies within $1.3 \mathrm{G}<\mathrm{W}<3.0 \mathrm{G}$;

$$
\begin{aligned}
& \text { Height of jaw }=4.0 \times \mathrm{G} \\
& \text { Throw }(\mathrm{x})=0.0502(\mathrm{G})^{0.85}
\end{aligned}
$$

However, observations during plant visits showed that some jaw heights are not up to $4 \mathrm{G}$ as given above, and the fixed jaws are shorter than the movable jaws. DeDiemar [32] noted that equation (3) yields the power required to crush the stone only, and advised that mechanical power to operate the crusher must be added to the determined power. Telsmith [33] noted that horsepower required varies with the size of the product, toughness of the rock or ore and the capacity of the crusher. The use of variable speed device or soft starter to reduce energy cost in jaw crushers has been suggested by Numbi et al. [34]. However, this suggestion did not take into cognizance the advantage of storing energy in the flywheel and the delay arising from intermittent switching.

A power consumption model developed by Donovan [9] for the selection and optimization of jaw crushers based on a few parameters and fracture toughness of the rock to be broken was based on the fact that the specific comminution energy required to reduce a rock particle to a given size increases with fracture toughness. Fracture toughness being an intrinsic material property expresses a material's resistance to crack propagation, and it is a measure of the energy required to create a new surface in a material. The relation between fracture toughness and specific comminution energy is given as follows:

$$
\begin{gathered}
P_{c}=\sum_{i=1}^{j}\left[-0.511+0.511 R R_{i}\right] K_{I C} C_{i} X_{i}+P_{n} \\
\text { for } 1 \leq R R \leq 1.5 \\
P_{c}=\sum_{i=1}^{j}\left[0.215 R R_{i}^{0.425}\right] \mathrm{K}_{I C} C_{i} X_{i}+P_{n}
\end{gathered}
$$

for $\mathrm{RR} \geq 1.5$

where, $\mathrm{P}_{\mathrm{c}}$ is the power consumption of the crusher in $\mathrm{kW}$, $R_{\mathrm{i}}$ is the reduction ratio for particle size $\mathrm{i}, \mathrm{K}_{\mathrm{IC}}$ is the fracture toughness of the rock being crushed in MPa.m ${ }^{1 / 2}$, $\mathrm{C}_{\mathrm{i}}$ is the probability of breakage of particle size $\mathrm{i}, \mathrm{X}_{\mathrm{i}}$ is the mass flow of particle size $i$ in metric tonnes per hour, and $P_{n}$ is the power drawn by the crusher under no load in $\mathrm{kW}$.

The Donovan model suggested that the toughest rock would consume $230 \%$ more power than the weakest for the same feed size and average reduction ratio. Laboratory size crusher was used to establish the model; hence, there is no certainty that industrial crushers will obey the equations.

These mathematical models describing the crushing processes will be advantageous for simulation and optimization purposes if they can describe the complete crushing process; hence, there is need for crushing models that would capture the pertinent parameters.

\section{CONCLUSIONS}

The major challenges faced by the single toggle jaw crusher emanate from the nature of the material to be crushed, angle of nip and components design. Strength and toughness of a rock are directly proportional to the comminution energy; hence, a rock particle with higher strength and toughness will require more time and energy to break under the influence of a jaw crusher. Angle of nip must be maintained between $17^{\circ}$ and $27^{\circ}$ as deviation from this range leads to undesirable and uneconomical output.

The diametric configuration of the eccentric shaft is the key to achieving better throw; consequently, increase in the throughput of the crusher can be achieved by increasing the eccentric lobe rather than increasing the width of the jaw. Wear on the jaw plates is more on the fixed jaw and increases as the material being crushed moves towards discharge. Reversible jaws have been used to reduce frequency of repair or replacement. Hard facing technique has been suggested as a means of taking 
care of the wear variation. Stiffened jaws give high strength to weight ratio and may require less energy. Honeycomb-structured pitman increases horizontal rigidity, demands less energy from the flywheel and accomplishes crushing task with less stroke count and length.

A toggle mechanism that will guarantee quick and easy removal of tramp iron without breaking the plate is still needed in the jaw crusher. Crushing force is derived from the action of the toggle plate and the inertia of the flywheel whose weight is counter-balanced by the pulley. The use of bush bearing reduces the mean time to repair and increases availability, as dismantling of the pulley and flywheel is avoided when repairing or replacing the bearing; this does not only increase customer satisfaction and productivity, but also reduces maintenance cost. Application of friction geomodifiers to worn parts such as bearings will reduce frequency of shutdown and maintenance cost and increase the service life of the equipment.

Proper structural analysis of the crusher frame should be carried out at design stage to prevent vibrations and fatigue cracks during operation. Power required to crush a material as given by Bond's equation did not include the mechanical power required to drive the movable jaw and toggle plate. The mechanical power need to be added to that of comminution prior to selecting a prime mover. Existing crushing power models are not all encompassing as important parameters as fracture toughness, compressive strength, reduction ratio, angle of nip, work index and jaw dimensions were not integrated in one model; hence, there is need to develop complete power model for the purposes of simulation and optimization of the jaw crusher, whether laboratory or industrial.

\section{REFERENCES}

[1] Mohamed, A., Gilbert, G. and Nicholas, M., 2014, "Mechanical design of a small scale mechanized stone crusher", Bachelor Degree Thesis, Department of Mechanical and manufacturing Engineering, University of Nairobi. 2014.

[2] Choudaha, S., Tiwari, S. K. and Pande, S. "Improving productivity of jaw crusher OTIF delivery by reducing down time", International Journal of Emerging Technology and Advanced Engineering, Vol. 2, Issue 10, pp. $403-410,2012$.

[3] Shrivastava, A. K. and Sharma, A. K. "A review on study of jaw crusher", International Journal of Modern Engineering Research, Vol. 2, Issue 3, pp. 885 - 888, 2012.

[4] Niemela, R. and Kieranen, C. "Portable apparatus for crushing rock and other hard materials and related method", US Patent No. 7,448,564 B2, 2008.
[5] Verma, D. R. and Hatwar, P. R. "Design of a Horizontal shaft impact crusher", International Journal of Application or Innovation in Engineering and Management, Vol. 3, Issue 1, pp. 82 - 90, 2014.

[6] Unland, G. and Szczelina, P. "Coarse crushing of brittle rocks compression", International Journal of mineral Processing, Vol. 74S, pp. S209 - S217, 2004.

[7] Lee, E. "Optimization of compressive crushing”, Ph. D. Thesis submitted to the Department of Product and Product Development, Chalmers University of Technology, Göteborg Sweden, 2012.

[8] Miller, R. B. "Crushing apparatus and method", US Patent No. 2014/0042253 A1, 2014.

[9] Donovan, J. G. "Fracture toughness based models for the prediction of power consumption, product size and capacity of jaw crushers", Ph. D. Dissertation in Mining and Minerals Engineering, Faculty of Virginia Polytechnic Institute and State University, Blacksburg, VA, 2003.

[10] Zeng, Y. and Forssberg, E. "Application of vibration signals to monitoring crushing parameters", Powder Technology, Vol. 76, pp. 247 - 252, 1993.

[11] Metso Minerals. "Nordberg C series jaw crusher". Technical publication: in Donovan, J. G. (2003). "Fracture toughness based models for the prediction of power consumption, product size and capacity of jaw crushers", Ph. D. Dissertation in Mining and Minerals Engineering, Faculty of Virginia Polytechnic Institute and State University, Blacksburg, VA, 2003.

[12] Ojo, O. and Olaleye, B. M. "Strength characteristics of two Nigerian rock types", Global Journal of Pure and Applied Sciences, Vol. 8, No. 4, pp. 541 -549. 2002.

[13] Refahi, A., Mohandesi, J. A. and Rezai, B. "Comparison between bond crushing energy and fracture energy of rocks in jaw crusher using numerical simulation", The Journal of the South African Institute of Mining and Metallurgy, Vol. 109, pp. 709 - 717, 2009.

[14] Elisante, E. "Simplification of jaw crusher for artisanal aggregate miners", Journal of Engineering and Technology Research, Vol. 1, No. 6, pp. 102 108, 2009.

[15] Olaleye, B. M. "Influence of some rock strength properties on jaw crusher performance in granite quarry", MiningScience and Technology, Vol. 20, No. 2, pp. $204-208,2010$.

[16] Kinkel, R. P. "Wear plate for jaw crushers", US Patent No. 2,449,746, 1948.

[17] Suresh, B. A. "Computer aided design and analysis of swing jaw plate of jaw crusher", A Master of Technology Thesis submitted to the Department of Mechanical Engineering, National Institute of Technology, Rourkela, 2009. 
[18] Karra, V. K., Magerowski, A. J. and Szalanski, S. E. "Method of high performance jaw crushing", US Patent No. 5,110,057, 1992.

[19] Sutti, R. and Jonkka, J. "Pitman of jaw crusher, crushing plant and crushing method", US Patent No. 2013/0043335 A1, 2013.

[20] Hulthén, E. "Real-time optimization of cone crushers", Ph. D. Thesis, Department of Product and Product Development, Chalmers University of Technology, Göteberg, Sweden, 2010.

[21] Taylor Jr., S. W. "Spring relief mechanism for jaw type crushers", US Patent No. 2,784,916, 1957.

[22] Omwenga, B. B., Yaa, M. G. and Robinson, M. N. "Kinematic and static force transmission analysis of a single toggle jaw crusher", A Bachelor Degree Thesis submitted to the Department of Mechanical and Manufacturing Engineering, University of Nairobi, 2014.

[23] Askeland, D. R. "The science and engineering of materials", $3^{\text {rd }}$ ed., PWS Publishing Company, Boston, 1994.

[24] Gorman, D. G. and Kennedy, W. "Applied solid dynamics", Butterworth and Co. (Publishers) Ltd, London, 1988.

[25] Khurmi, R. S. and Gupta, J. K. "Theory of machines", Eurasia Publishing House (Pvt) Ltd, New Delhi, 2005.

[26] Didyk, R. P. and Aratskiy, P. B. "Increase of mining and smelting equipment life on the way of tribological barrier overcoming", Science of
Machines: Metallurgical and Mining Industry, Vol. 3, No. 2, pp. 67 - 72, 2011.

[27] Rusiński, E., Moczko, P., Pietrusiak, D. and Przybyłek, G. "Experimental and numerical studies of jaw crusher supporting structure fatigue failure", Strojniški Vestnik - Journal of Mechanical Engineering, Vol. 59, No. 9, pp. 556 - 563, 2013.

[28] Wills, B. A. "Mineral Processing Technology: An Introduction to the practical aspects of ore treatment and mineral recovery", $5^{\text {th }}$ Ed., Pergamon Press, New York, 1992.

[29] Zhang, J. "Particle technology-Study notes", http://lorien.ncl.ac.uk/ming /particle/cpe124p4.html, Accessed on September 9, 2014.

[30] Kelly, E. G. and Spottiswood D. J. “Introduction to mineral processing", John Wiley and Sons, Inc., Canada, 1982.

[31] More, R. S. and Rajpal, S. J. "A review on the study of jaw plates of jaw crusher", International Journal of Modern Engineering Research, Vol.3, Issue 1, pp. 518 - 522, 2013.

[32] DeDiemar, R. B. "New concepts in jaw crusher technology", Minerals Engineering, Vol. 3, No. 1/2, pp. $67-74,1990$.

[33] Telsmith, "Mineral processing handbook", Third edition, Telsmith Inc., U.S. A., 2011.

[34] Numbi, B. P., Zhang, J. and Xia, X. "Optimal energy management for a jaw crushing process in deep mines", Energy, Vol. 68, pp 337 - 348, 2014. 